\title{
Robotic Light Following System
}

\author{
Prince Samuel $\mathrm{S}^{1}$, Felvin $\mathrm{K} \mathrm{F}^{2}$, Vikash $\mathrm{J}^{3}$, Shankar $\mathrm{M}^{4}$ \\ 1 Assistant Professor, Department of EIE, SNS College of Technology, Coimbatore, India \\ 2 UG Scholar, Department of EIE, SNS College of Technology, Coimbatore, India \\ 3 UG Scholar, Department of EIE, SNS College of Technology, Coimbatore, India \\ 4 UG Scholar, Department of EIE, SNS College of Technology, Coimbatore, India \\ princesamuel239@gmail.com ${ }^{1}$, \\ felvin18297@gmail.com ${ }^{2}$, \\ snsvikash@gmail.com ${ }^{3}$, \\ shankarsm1522@gmail.com ${ }^{4}$
}

\begin{abstract}
This project demonstrates the creation of a robot using low cost light controlled variable resistor to follow a flash light. It also demonstrates a very simple control loop. A control loop is an important concept in the world of robotics. Control loops are used for everything from regulating the speed of the motors to helping the robot travel in the path of higher luminescence across all directions. It is based on the principle that resistance of a LDR changes with the amount of light falling on it. The resistance of an LDR will decrease with increase in luminescence. This variation is fed to a comparator with a reference voltage set. This drives the robot in the desired direction with the help of DC motors.
\end{abstract}

$* * * * *$

\section{INTRODUCTION}

Light following robot is a robot that senses the light and follows it. A user can shine a flashlight at its front and it will respond by following the light source. This is designed without using a micro controller. When a LDR (Light Dependent Resistor) subjected to white light then the resistance varies. According to this variation Op-amp circuit gives response to drive the motor. Light is incident on LDR Resistance and changes Op-amp which sends signal. Simulation is a process of testing the design by applying inputs to a circuit and watching or observing its behavior. The output of a simulation is a set of waveforms that show how a circuit behaves upon a given sequence of inputs. In this project, simulation is done using PROTEUS which is the most famous PCB design software. It is integrated with the simulation and basic SPICE simulation capability to make a complete electronics design system. It reduces development time when compared with other embedded design process.

\section{DRIVERS}

A. IC L293DL293D is an motor driver IC and it is an 16 pin IC which is used to control and drive the motor simultaneously in either directions that is clockwise or anticlockwise direction. it means by using single L293D IC we can control two DC motors. It can drive small motors as well as the large motors. It works on the concept of $\mathrm{H}$ bridge, because it will allows the voltage to be flown in two directions. As you know, for driving the motor in two different directions the voltage need to be changed its direction of flow. Hence H-bridge is ideal for driving the motors. Due to its small in size it is very much used in robotics application for driving and controlling the DC motors.L293D requires $5 \mathrm{~V}$ in VCC as an internal voltage and VSS is the input supply for driving the motor. The maximum voltage of VSS is $36 \mathrm{~V}$.the table shows the pin number and its logical operations.

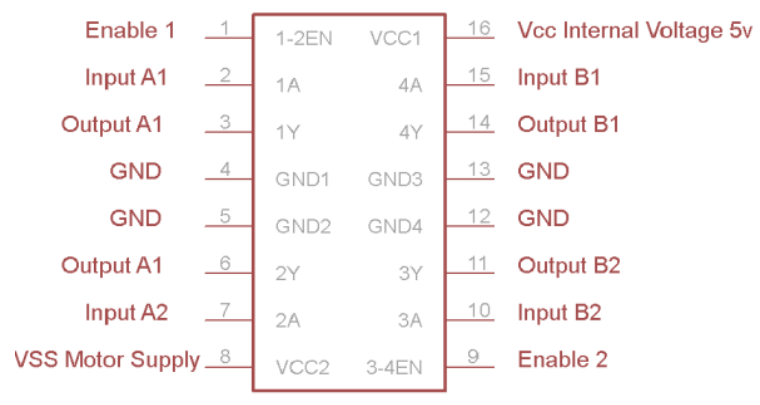

Figure 1 Pin Diagram Of IC L293d

TABLE 1: Pin Number And Its Logical Operations

\begin{tabular}{|c|c|c|}
\hline PIN NUMBER & LOGIC & $\begin{array}{c}\text { DIRECTION OF } \\
\text { ROTATION }\end{array}$ \\
\cline { 1 - 2 } 2 & 1 & $\begin{array}{c}\text { CLOCKWISE } \\
\text { DIRECTION }\end{array}$ \\
\cline { 1 - 2 } ANTI-CLOCKWISE \\
DIRECTION
\end{tabular}


B.IC LM358: LM358 is an 8 pin voltage comparator IC. It is used in transducer amplifier and all the conventional operational amplifier circuits. It is easily implemented in single power supply systems. It consist of two internally compensated op-amps.it does not requires dual supply. It has inverting and non- inverting terminals. If the noninverting terminal voltage is less than the inverting terminal voltage then the output of the comparator is low. And if the non-inverting input is higher than the inverting input then the comparator output will be high.

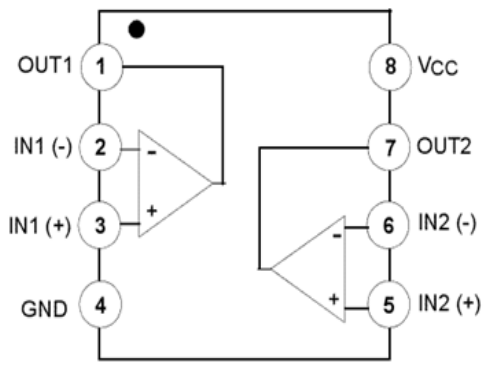

Figure 2 Pin Diagram of IC LM358

TABLE 2: Pin Number and Logical Operations of Lm358

\begin{tabular}{|c|c|}
\hline PIN NUMBER & DESCRIPTION \\
\cline { 1 - 1 } 1 & \multirow{2}{*}{ Comparator output } \\
\hline 7 & \multirow{2}{*}{ Inverting input } \\
\hline 2 & Non-inverting input \\
\hline 3 & Ground \\
\hline 5 & Supply(VC) \\
\hline 4 &
\end{tabular}

III. LIGHT DEPENDENT RESISTOR

The LDR is the light controlled variable resistor. The resistance of the LDR decreases with increase in light intensity and vice versa. It is made up of high resistance semiconductor. In the dark the LDR has resistance value as high as few mega ohms. While in the light it has the resistance value as low as few hundred ohms. The sensitivity and the range of the LDR should varies for different devices.

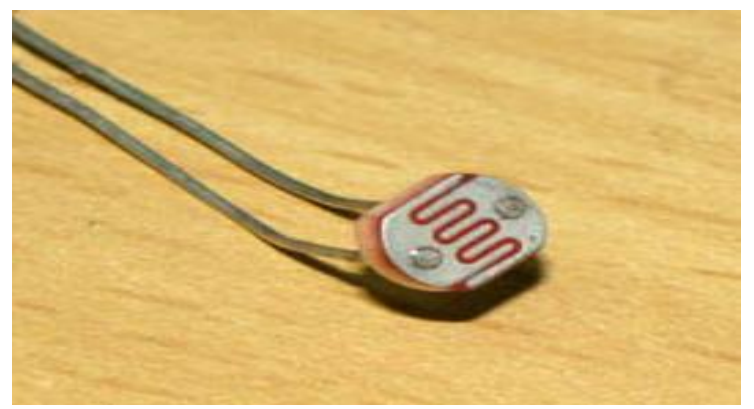

Figure 3 Light Dependent Resistors

\section{BATTERY AND BREADBOARD}

A battery is an electronic device used to store energy and reuse it. It consist of one or more electrochemical cells that coverts stored chemical energy into electrical energy. Each cell contains a positive terminal or cathode and negative terminal called cathode. In our work, we use $9 \mathrm{~V}$ battery for powering the robot. For more usages two pair of $9 \mathrm{~V}$ battery is used. The bread board is the base for external electronic devices. In our work, we interface the IC's, LDR, battery and an motor in the single bread board.

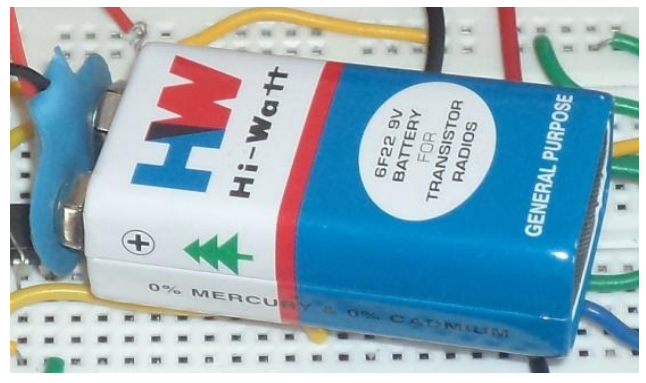

Figure 4 Battery and Breadboard

\section{MOTORS}

A motor is a device which converts electrical energy into mechanical energy. It is based on the principle of electromagnetic induction.in our work we use two 300rpm dc motors to run the robot.

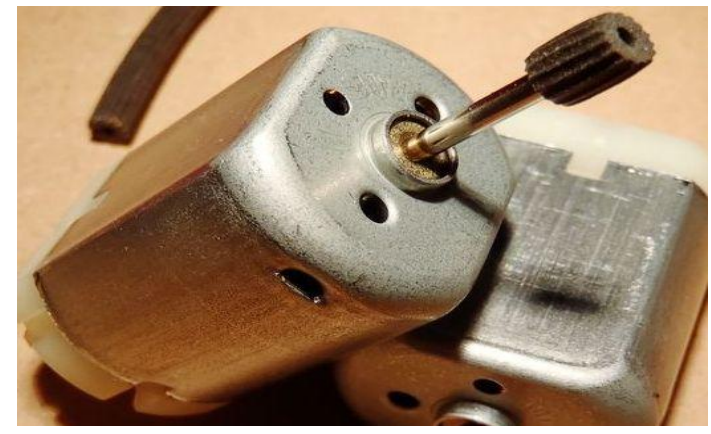

Figure 5 Motor

VI. BLOCK DIAGRAM

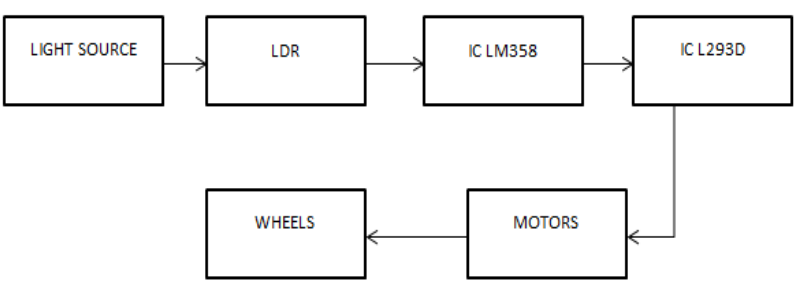

Figure 6 Block Diagram

Connect a $9 \mathrm{~V}$ battery to the breadboard. Then connect an IC LM358 in the breadboard .As it is a voltage comparator, it guess the output from the LDR depends on the input voltage. For example, let us consider that the voltage at 
$3^{\text {rd }}$ pin is higher than or equal to the voltage at $2^{\text {nd }}$ pin. At this time, the $1^{\text {st }}$ pin of IC LM358 will be high otherwise it will be low. A resistor of 10k is attached with each LDR. Then, place an IC L293D in the breadboard, and join the $2^{\text {nd }}$ and $15^{\text {th }}$ pin of it with IC LM $3581^{\text {st }}$ pin. The left motor is connected to the $3^{\text {rd }} \& 6^{\text {th }}$ pin of IC L293D and the right motor is connected to the $11^{\text {th }} \& 14^{\text {th }}$ pin. The wheels are fixed with the motors. A castor wheel is attached at the front of the robot for balanced movements. A power supply of $5 \mathrm{~V}$ is applied to the $1^{\text {st }}, 7^{\text {th }}, 8^{\text {th }}, 9^{\text {th }}, \& 16^{\text {th }}$ pins. The residual $4^{\text {th }}, 5^{\text {th }}, 10^{\text {th }}, 12^{\text {th }}, \& 13^{\text {th }}$ pins are connected to the ground. When the light focuses on the right LDR, the robot will move on the right side by the clockwise rotation of motor. Similarly, the robot will move on the left side when the light focuses on the left LDR by the rotation of motors in anti-clockwise direction.

\section{SIMULATION RESULTS}

The simulation of our project is in the proteus 8 which is shown below. The simulation results show the motor running while the LDR is turned on.

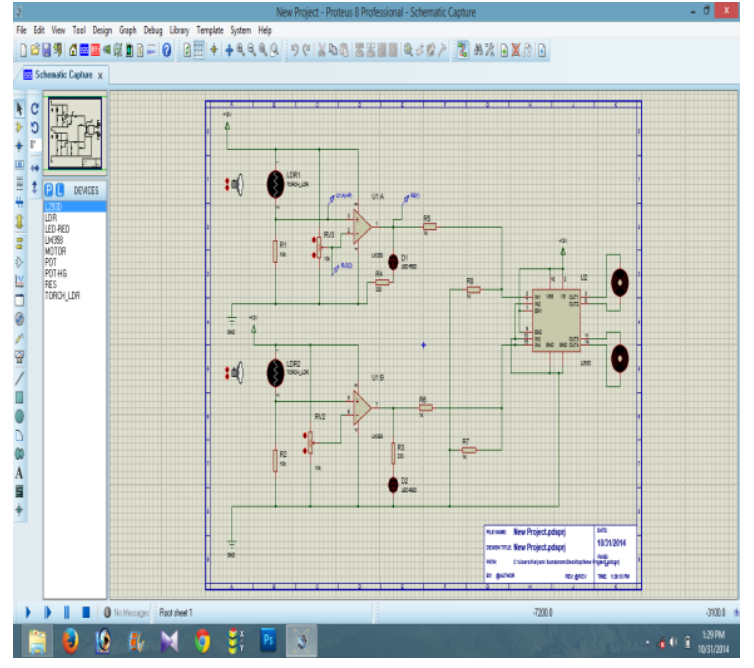

VIII. APPLICATIONS

Light following robots are used in street lights and alarm devices. This technology can also be used to measure light intensity for applications that require greater precision Cameras can use this technology to determine the proper exposure time Laptops may use in a circuit that varies screen brightness according to ambient lighting conditions It could be used as a watch dog robot which sends an email to the cell phone when detects light in the house which should be off. It is also used in military and manufacturing support It can even be employed in security systems

\section{CONCLUSION}

In this paper a robot which follows light without using a microcontroller is designed and simulated using PROTEUS
8. In our future work we will use raspberry pi to control the robot and simulate it by using LABVIEW. The raspberry pi is simple to use, budget-friendly. It is self-assembled kit that allows us to control the DC motor with very little coding.

\section{REFERENCES}

[1]. http://www.onsemi.com/pub/Collateral/LM358-D.PDF

[2]. http://www.chipswinner.com/ends/LM358.pdf

[3]. http://www.datasheetcatalog.com/datasheets_pdf/L/M/3/5/ LM358.shtml

[4]. http://www.rakeshmondal.info/L293D-Motor-Driver Figure 7 Simulation Result (Proteus) 